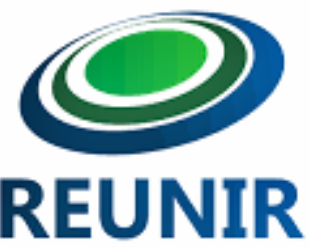

REUNIR:

Revista de Administração,

Ciências Contábeis e

Sustentabilidade

www.reunir.revistas.ufcg.edu.br

ARTIGO ORIGINAL

\title{
Efeito da governança corporativa nos honorários de auditoria em empresas brasileiras ${ }^{1}$
}

\author{
Effect of corporate governance in audit fees in brazilian
}

\section{Efecto de la gobernanza corporativa en los honorarios de auditoría en empresas brasileñas}

\author{
Alini da Silva ${ }^{2}$, Caroline Sulzbach Pletsch ${ }^{3}$, Paulo Roberto da Cunha ${ }^{4}$
}

PALAVRAS-CHAVE

Governança

corporativa;

Honorários de

auditoria; Teoria da

Sinalização.

\begin{abstract}
Resumo: 0 presente estudo teve por objetivo verificar o efeito da governança corporativa nos honorários de auditoria em empresas brasileiras. Para analisar esta relação de influência utilizou-se da Teoria da Sinalização. A metodologia utilizada quanto aos objetivos configurou-se como descritiva, em relação aos procedimentos como documental e referente à abordagem é quantitativa. A população compreendeu todas as empresas listadas na BM\&FBOVESPA, e a amostra foi composta por 214 empresas, as quais detinham todas as informações necessárias para a realização do estudo no período analisado, que correspondeu ao ano de 2013. Pela abordagem quantitativa do problema, para a análise dos dados utilizou-se de técnicas estatísticas como análise descritiva e regressão linear múltipla. Os resultados demonstraram que quanto maior o tamanho da empresa, maiores os honorários de auditoria e que o saldo de contas a receber não impactou no aumento dos honorários de auditoria, por não representar risco empresarial, demonstrando efeito significativo para a redução dos honorários de auditoria. Desta forma, a hipótese 2 formulada foi aceita parcialmente e quanto a hipótese 1 , sobre o efeito da governança corporativa nos honorários de auditoria, não pode-se confirmá-la, visto que a governança corporativa não apresentou influência significativa nos honorários de auditoria, porém demonstrou relação positiva, corroborando em parte sobre a inferência da Teoria da Sinalização.
\end{abstract}

\section{KEYWORDS}

Corporate Governance; Audit fees; Theory of Signs.

\begin{abstract}
The present study aimed to verify the effect of corporate governance on audit fees in Brazilian companies. To analyze this relationship of influence was used the Signaling Theory. The methodology used for the objectives was set out as descriptive, in relation to the procedures as documentary and referring to the approach is quantitative. The population comprised all the companies listed on the BM \& FBOVESPA, and the sample consisted of 214 companies, which had all the necessary information to carry out the study during the analyzed period, which corresponded to the year 2013. By the quantitative approach of the problem, for the Data analysis was performed using statistical techniques such as descriptive analysis and multiple linear regression. The
\end{abstract}

\footnotetext{
1 Submetido em 23/01/2018. Aceite em 28/12/2018. Publicado em 05/02/2019. Responsável Universidade Federal de Campina Grande/UACC/PROFIAP/CCJS/UFCG.

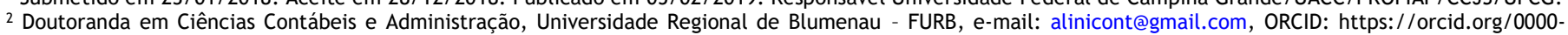
0002-7043-5566

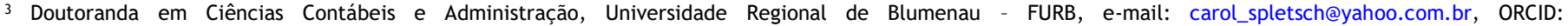
https: / /orcid.org/0000-0002-1978-2204

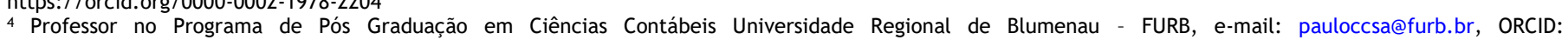
https://orcid.org/0000-0001-5805-9329
} 
results showed that the larger the company size, the higher the audit fees and the balance of accounts receivable did not impact on the increase in audit fees, as it did not represent a corporate risk, demonstrating a significant effect on the reduction of audit fees. In this way, hypothesis 2 was partially accepted and in hypothesis 1 , on the effect of corporate governance in audit fees, it can not be confirmed, since corporate governance did not have a significant influence on audit fees, however demonstrated a positive relation, corroborating in part on the inference of the Signaling Theory.

PALABRAS CLAVE

Gobernanza

corporativa; Honorarios de auditoría; Teoría de la Señalización.
Resumen: El presente estudio tuvo por objetivo verificar el efecto de la gobernanza corporativa en los honorarios de auditoría en empresas brasileñas. Para analizar esta relación de influencia se utilizó la Teoría de la Señalización. La metodología utilizada en cuanto a los objetivos se configuró como descriptiva, en relación a los procedimientos como documental y referente al abordaje es cuantitativa. La población comprendió todas las empresas listadas en la BM \& FBOVESPA, y la muestra fue compuesta por 214 empresas, las cuales tenían toda la información necesaria para la realización del estudio en el período analizado, que correspondió al año 2013. Por el abordaje cuantitativo del problema, el análisis de los datos se utilizó de técnicas estadísticas como análisis descriptivo y regresión lineal múltiple. Los resultados demostraron que cuanto mayor es el tamaño de la empresa, mayores los honorarios de auditoría y que el saldo de cuentas a cobrar no impactó en el aumento de los honorarios de auditoría, por no representar riesgo empresarial, demostrando efecto significativo para la reducción de los honorarios de auditoría. De esta forma, la hipótesis 2 formulada fue aceptada parcialmente y en cuanto a la hipótesis 1, sobre el efecto de la gobernanza corporativa en los honorarios de auditoría, no se puede confirmarla, ya que la gobernanza corporativa no presentó una influencia significativa en los honorarios de auditoría, pero demostró relación positiva, corroborando en parte sobre la inferencia de la Teoría de la Señalización. 


\section{Introdução}

Gestores de empresas sinalizam ao mercado algumas particularidades e diferenciais organizacionais, a fim de obterem legitimação e reafirmarem seu desempenho e estrutura empresarial perante os usuários externos. A governança corporativa, de acordo com Wu (2012) é um método de sinalização para o mercado, ou seja, empresas que adotam elementos exigidos pela governança corporativa emitem sinal ao mercado, quanto a sua adequação a esta estrutura organizacional, que fornece maior transparência e fidedignidade em relação às atividades empresariais.

A governança corporativa é descrita como mecanismos, regras, leis ou princípios de empresas, que tem por intuito a minimização de conflitos na relação entre principais e agentes, auxiliando no processo decisório (CARVALHO, 2002). A adoção de práticas diferenciadas de governança corporativa é considerada sinal ao mercado, desde que assegure a qualidade informacional de relatórios, influenciando por sua vez a opinião de analistas de mercado, por auxiliar na diminuição da assimetria informacional entre a empresa e os usuários do mercado de capitais. Na emissão de sinais ao mercado, a empresa dispende gastos, conhecidos por custos de sinalização (DALMÁCIO, 2009).

Há indícios de que empresas com governança corporativa contratam auditoria externa mais rigorosa, para emitirem sinais ao mercado de qualidade, impactando em elevados honorários de auditoria (WU, 2012). Neste contexto, apresenta-se o problema de pesquisa: os honorários de auditoria são afetados pela governança corporativa em empresas brasileiras? A fim de auxiliar na resolução da problemática, o objetivo de pesquisa consiste em verificar o efeito da governança corporativa nos honorários de auditoria em empresas brasileiras.

Estudos nacionais e internacionais analisaram possíveis efeitos sobre os honorários de auditoria, dentre eles verificaram a influência da governança corporativa. Wu (2012) investigou empiricamente a relação entre governança corporativa e honorários de auditoria em empresas chinesas. Griffin, Lont e Sun (2008) verificaram a relação entre honorários de auditoria, qualidade da auditoria e governança corporativa, os quais testaram a hipótese de que o aumento dos honorários de auditoria causa mudanças na qualidade da auditoria e melhora na governança corporativa.

Hallak e Silva (2012) identificaram os fatores que influenciam na determinação de gastos com auditoria e consultoria por parte das empresas brasileiras abertas. Bortolon et al. (2013) analisaram a relação entre governança corporativa, custos de auditoria e serviços de não auditoria de empresas brasileiras. Também, estudos como Francis (1984) e Choi et al. (2008) analisaram empiricamente alguns efeitos sobre os honorários de auditoria, mais especificamente verificaram a influência do tipo de empresa de auditoria.

A presente pesquisa supre a lacuna de analisar o efeito da governança corporativa nos honorários de auditoria de empresas brasileiras, pela ótica da teoria da sinalização. A auditoria externa cobra honorários de auditoria elevados para assegurar as práticas de governança corporativa, em que estas práticas são sinalizadas ao mercado, impactando na opinião de analistas e demais usuários externos. Desta forma, verifica-se esta hipótese dedutiva com elementos de governança e honorários de auditoria no cenário de empresas brasileiras, contribuindo com o avanço da teoria da sinalização, com explicações sobre a governança corporativa como sinal ao mercado e honorários de auditoria como custo de sinalização.

Justifica-se o estudo pela contribuição teórica e empírica à teoria da sinalização, utilizando-a para auxiliar na análise sobre a relação entre governança corporativa e honorários de auditoria a nível nacional, visto que esta teoria encontra-se de forma incipiente em pesquisas na área de ciências sociais aplicadas.

\section{Elementos teóricos da pesquisa}

\section{Teoria da sinalização}

A Teoria da Sinalização procura demonstrar como os problemas de assimetria informacional nos mercados, podem ser reduzidos pela sinalização de informações. A sinalização de acordo com esta teoria é capaz de alterar crenças pela transmissão de informações aos usuários. Desta forma, caso há assimetria informacional em empresas, podem-se divulgar informações necessárias aos interessados, para diminuir ou eliminar esta assimetria. Para atrair novos investimentos e recursos, as empresas sinalizam ao mercado informações organizacionais, como adoção de práticas diferenciadas de governança corporativa, que pode representar qualidade e credibilidade empresarial. Quando da emissão de sinalização de informações ao mercado, a empresa dispende gastos, chamados de custos de sinalização, pois quando adota mecanismos de governança corporativa, por exemplo, custa caro a empresa. Entretanto, estes custos de sinalização geram expectativa à empresa, de que os benefícios que podem ocorrer pela entrada de novos investidores, sejam superiores aos gastos dispendidos (DALMÁCIO, 2009).

Um sinal não distingue um candidato ou empresa de outro, a menos que os custos de sinalização apresentem relação negativa com a capacidade de produção. Os sinais são modificáveis e sujeitos a manipulação dos gestores de acordo com seus interesses, desde que arcando com custos de sinalização (SPENCE, 1973). Para Wu (2012), os sinais referentes ao nível de governança corporativa da empresa, divulgados aos usuários interessados, faz com que a auditoria externa seja mais rigorosa, elevando os honorários de auditoria. Por tal motivo, as empresas que possuem práticas de governança corporativa diferenciadas, pagam altos honorários de auditoria, em que estes gastos elevados de auditoria, pela teoria da sinalização, são considerados custos de sinalização.

Segundo Dalmácio (2009), quando as empresas adotam práticas comuns de governança e divulgam informações convencionais ao mercado, podem não atingir a eficácia que o mercado deseja, de acordo com a teoria da sinalização. Desta forma, as organizações adotam práticas diferenciadas em suas atividades, com o intuito de amplificar os sinais emitidos aos usuários, informando às partes desinformadas, a qualidade, integridade e credibilidade informacional; valor de mercado das ações; controle e monitoramento das ações dos gestores; menor volatilidade das ações; menor custo de capital e de captação; desempenho operacional; dentre outras características.

Tem-se gerado estudos teóricos e empíricos na contabilidade, a fim de entender a capacidade das empresas 
em sinalizar informações com qualidade e potenciais aos investidores e ao mercado, como uma oferta pública da organização. Os pressupostos da teoria da sinalização são que os proprietários de organizações de alta qualidade divulgam informações para diminuir assimetria, desembolsando valores por isso, que empresas de baixa qualidade não são capazes de realizar (CAl et al., 2007).

A teoria da sinalização, conforme Dionne e Ouederni (2010), sugere relação entre assimetria da informação e política de dividendos, quanto maior for a assimetria informacional, maior a volatilidade de dividendos. Autores nacionais e internacionais investigaram ao longo dos anos, possíveis relações entre a teoria da sinalização e cenários empresariais, como redutora de assimetria informacional.

Cai et al. (2007) realizaram teste sobre a teoria da sinalização e o sucesso ou fracasso de empresas, de acordo com alta ou baixa qualidade empresarial. Os resultados demonstraram que empresas com alta qualidade sinalizam informações aos investidores por meio do patrimônio líquido retido.

Wang et al. (2009) analisaram o conservadorismo contábil como sinalização de informações sobre risco operacional da empresa para os usuários, sem ter assinado contrato de dívida. Os achados demonstraram que o conservadorismo contábil é utilizado como mecanismo de sinalização, reduzindo assimetria informacional sobre o risco da empresa quanto à dívida ao mercado.

Dionne e Ouederni (2010) investigaram a assimetria da informação por meio da teoria da sinalização, com a política de dividendos e gestão de risco. A gestão de risco reduz a assimetria da informação, que é determinante para a política de dividendos. Os resultados apresentaram que a gestão de risco corporativo reduz as alterações de dividendos, prevendo as futuras mudanças de ganhos.

\section{Governança corporativa}

Governança Corporativa é conceituada pelo IBGC (2004, p. 19) como "sistema pelo qual as organizações são dirigidas, monitoradas e incentivadas, envolvendo os relacionamentos entre proprietários, Conselho de Administração, Diretoria e órgãos de controle”. Ainda, é destacado pelo IBGC (2004) que as boas práticas de Governança Corporativa contribuem para preservar e potencializar o valor da organização.

Hasan e Butt (2009) definem Governança Corporativa como um mecanismo que envolve processos, estrutura e gestão dos assuntos corporativos, que contribuem para a criação de valor para os acionistas, assegurando o interesse individual e coletivo dos stakeholders. Para Shleifer e Vishny (1997), a Governança Corporativa possui como questão fundamental garantir que os investidores da organização obtenham um retorno dos seus investimentos. La Porta et al. (2000) acrescentam que a Governança Corporativa eficaz está associada com a proteção dos investidores, quanto a seus direitos de propriedade.

Ehikioya (2009) destaca que um sistema de governança bem definido contribui para atrair investimentos, captar recursos, avigorar o desempenho da empresa, além de proteger a organização de vulnerabilidades futuras. É por meio do conselho de administração, que os acionistas incentivam as ações dos gerentes da empresa, com o intuito de atender os interesses daqueles que fornecem financiamento e de outras partes interessadas. Desta forma, a importância de boas práticas de Governança Corporativa começa a ser percebida por investidores e partes interessadas.

Segundo Hasan e Butt (2009), os princípios de Governança Corporativa são a base que transmite confiança aos investidores e credores, em que boas práticas de governança podem influenciar nas decisões estratégias de uma organização. Os princípios básicos de Governança Corporativa compreendem a transparência, equidade, prestação de contas (accountability) e responsabilidade corporativa (IBGC, 2004). No Quadro 1 apresenta-se os princípios e sua explicação.

\begin{tabular}{|l|l|}
\hline Princípios & Explicação \\
\hline Transparência & $\begin{array}{l}\text { Disponibilizar informações que sejam de } \\
\text { interesse das partes interessadas e não } \\
\text { somente informações que são exigidas por } \\
\text { leis ou regulamentos, o que transmite } \\
\text { confiança, tanto interna quanto externa. }\end{array}$ \\
\hline Equidade & $\begin{array}{l}\text { Tratamento justo de todos os sócios e partes } \\
\text { interessadas. }\end{array}$ \\
\hline $\begin{array}{l}\text { Prestação } \\
\text { (accountability) }\end{array}$ & $\begin{array}{l}\text { Agentes de governança precisam prestar } \\
\text { contas. }\end{array}$ \\
\hline $\begin{array}{l}\text { Responsabilidade } \\
\text { Corporativa }\end{array}$ & $\begin{array}{l}\text { A sustentabilidade das organizações deve ser } \\
\text { zelada pelos agentes de governança, } \\
\text { incluindo aspectos de ordem social e } \\
\text { ambiental na definição dos negócios e } \\
\text { operações, com o objetivo da continuidade } \\
\text { da empresa. }\end{array}$ \\
\hline
\end{tabular}

Quadro 1 - Princípios de Governança

Fonte: Adaptado de IBGC (2004).

Governança Corporativa - GC, para Fazlzadeh et al. (2011) é considerada um fator essencial para o crescimento e desenvolvimento da organização e além disso, de acordo com Love (2010), contribui em ganhos de eficiência e na criação de valor para a empresa.

A Bolsa de Valores, Mercadorias e Futuros de São Paulo (BM\&FBOVESPA), ao perceber que para desenvolver o mercado de capitais brasileiros, era necessário segmentar as empresas de acordo com o perfil de cada uma, criou os níveis de Governança Corporativa: Bovespa Mais, Novo Mercado, Nível 2 e Nível 1 (BM\&FBOVESPA, 2014). Apresenta-se no Quadro 2 essa classificação.

\begin{tabular}{|l|l|}
\hline $\begin{array}{l}\text { Nível de } \\
\text { GC }\end{array}$ & Descrição \\
\hline \multirow{3}{*}{$\begin{array}{l}\text { Bovespa } \\
\text { Mais }\end{array}$} & $\begin{array}{l}\text { O objetivo é fomentar o crescimento de pequenas e } \\
\text { médias empresas via mercado de capitais; criado para } \\
\text { gradual; permite que a empresa se prepare e ao } \\
\text { mesmo tempo aumenta sua visibilidade para os } \\
\text { investidores. }\end{array}$ \\
\hline \multirow{5}{*}{$\begin{array}{l}\text { Nefere-se a um padrão de governança corporativa } \\
\text { Mercado }\end{array}$} & $\begin{array}{l}\text { altamente diferenciado; padrão de transparência } \\
\text { exigido pelos investidores para novas aberturas de } \\
\text { adicionais às exigidas pela legislação brasileira; adoção } \\
\text { de um conjunto de regras societárias que ampliam os } \\
\text { direitos dos acionistas; política de divulgação de } \\
\text { informações mais transparentes. }\end{array}$ \\
\hline \multirow{2}{*}{ Nível 2} & $\begin{array}{l}\text { Similar ao Novo Mercado; as empresas têm o direito de } \\
\text { manter ações preferenciais; no caso de venda de } \\
\text { controle da empresa, é garantido aos detentores de }\end{array}$ \\
\hline
\end{tabular}




\begin{tabular}{|l|l|}
\hline & $\begin{array}{l}\text { ações ordinárias e preferenciais o mesmo tratamento } \\
\text { concedido ao acionista controlador. }\end{array}$ \\
\hline Nível 1 & $\begin{array}{l}\text { Adotar práticas que favoreçam a transparência e o } \\
\text { acesso às informações pelos investidores; divulgam } \\
\text { informações adicionais às exigidas em lei. }\end{array}$ \\
\hline
\end{tabular}

Quadro 2 - Níveis de Governança Corporativa

Fonte: BM\&FBovespa (2014).

Todos os níveis presam por regras rígidas de governança, que vão além das obrigações que as empresas têm diante da Lei das Sociedades por Ações, o que atrai os investidores, ao garantir os direitos dos acionistas, bem como contribui para a divulgação de informações mais completas e transparentes (BM\&FBOVESPA, 2014).

Dalmácio (2009) destaca que, a adoção de práticas diferenciadas de Governança Corporativa é uma forma de sinalizar o mercado, para atrair novos investimentos e recursos. Dessa forma, de acordo com Bortolon et al. (2013), estudos demonstram que melhores práticas de governança tendem a influenciar no valor pago de honorários de auditoria, podendo resultar ou não em honorários mais elevados, na medida que o trabalho a ser desenvolvido demanda maior esforço e tempo, consequentemente os honorários tendem a ser mais elevados do que para empresas que representem uma redução no risco de auditoria.

\section{Construção das hipóteses}

Para verificar o efeito da governança corporativa nos honorários de auditoria, foram abordados alguns estudos que tratam sobre o tema, os quais contribuíram para a construção das hipóteses deste estudo.

Empresas com baixos níveis de governança corporativa tendem a possuir riscos elevados, assim, auditores precisam estar mais tempo na organização, precisam realizar mais trabalhos de auditoria e correm mais riscos de auditoria, consequentemente, os honorários de auditoria serão mais elevados. Entretanto, empresas com alto nível de governança corporativa, por exigirem maiores trabalhos de auditoria, para sinalizar o seu nível de governança para o mercado e melhorar o valor da empresa, também tendem a pagar valores elevados de honorários de auditoria (WU, 2012).

Empresas com um nível elevado de governança corporativa pagam valores mais altos de honorários de auditoria para ter melhores resultados da auditoria (GRIFFIN et al., 2008), aumentar sua eficiência e melhorar os controles internos (HALLAK; SILVA, 2012).

Hallak e Silva (2012) encontraram em seu estudo uma relação positiva entre a qualidade das práticas de governança e os honorários de auditoria. Esse achado demonstra que empresas com níveis de governança corporativa gastam mais com auditoria, com o objetivo de ter serviços de melhor qualidade e demonstrarem informações financeiras precisas e de confiança.

Wu (2012) encontrou uma relação negativa significativa entre governança corporativa e honorários de auditoria. Constatou ainda que o crescimento da empresa possui influência nesta relação, ou seja, em empresas da amostra que tiveram um crescimento moderado no período analisado, houve uma relação negativa significativa, enquanto que nas empresas da amostra que tiveram um crescimento rápido, não houve significância.
No estudo de Bortolon et al. (2013) o nível de governança corporativa não apresentou significância com os honorários de auditoria. Os autores destacam que nas empresas analisadas, uma melhor governança reduz o risco de auditoria, o que reflete na redução dos honorários de auditoria.

Assim, estabeleceu-se a primeira hipótese de pesquisa: $\mathrm{H} 1$ : $\mathrm{O}$ nível de governança corporativa possui relação significativa com os honorários de auditoria.

Estudos realizados demonstraram que a empresa de auditoria (FRANCIS, 1984; YATIM et al., 2006; WU, 2012; HALLAK; SILVA, 2012; CHOI et al., 2008), tamanho (YATIM et al., 2006; WU, 2012; HALLAK; SILVA, 2012), número de subsidiárias (YATIM et al., 2006; WU, 2012), crescimento (WU, 2012), ROA (YATIM et al., 2006; WU, 2012), alavancagem (YATIM et al., 2006; WU, 2012; HALLAK; SILVA, 2012), contas a receber e estoque (YATIM et al., 2006; WU, 2012) possuem influência nos honorários de auditoria.

Quanto às empresas de auditoria, espera-se que empresas de auditoria Big Four estejam relacionadas positivamente com os honorários de auditoria (YATIM et al., 2006; WU, 2012). Empresas de auditoria Big Four são mais especializadas e possuem vários escritórios que podem realizar os trabalhos para as empresas (FRANCIS, 1984). Hallak e Silva (2012) acrescentam que em decorrência da maior qualidade dos serviços prestados por empresas de auditoria Big Four, deveria resultar em maior valor nos honorários de auditoria.

No estudo de Francis (1984) os resultados demonstraram que empresas de auditoria Big Four estão relacionadas com honorários de auditoria elevados, devido à demanda diferenciada, a qualidade dos serviços prestados e a reputação.

Choi et al. (2008) verificaram que empresas de auditoria Big Four cobram valores mais elevados de honorários de auditoria do que empresas não Big Four. Hallak e Silva (2012) também constataram que a contratação de empresas de auditoria Big Four eleva as despesas com auditoria. Wu (2012) encontrou uma relação significativa e positiva entre a empresa de auditoria e os honorários de auditoria.

No que se refere ao tamanho da empresa, quanto maior a empresa, maiores são suas atividades de negócios e maior a contabilidade, o que acarreta em maior trabalho para a auditoria e consequentemente, em maiores valores de honorários (WU, 2012). Hallak e Silva (2012) acrescentam que a relação entre o tamanho da empresa e honorários de auditoria deve ser positiva, em decorrência de que empresas maiores possuem serviços mais complexos e o trabalho a ser realizado demanda mais tempo, em comparação com empresas menores.

Segundo Yatim et al. (2006) espera-se que os honorários de auditoria estejam relacionados positivamente com o tamanho. No estudo de Yatim et al. (2006) e Wu (2012) o tamanho da empresa apresentou relação significativa e positiva com os honorários de auditoria. Hallak e Silva (2012) encontraram uma relação positiva entre tamanho da empresa e honorários de auditoria, devido à complexidade do trabalho a ser realizado em empresas maiores.

Em referência ao número de subsidiárias, que 
representa a complexidade da empresa, espera-se que quanto mais complexa a empresa, maior seja o valor de honorários pagos à auditoria (WU, 2012). Segundo Yatim et al. (2006) espera-se que os honorários de auditoria estejam relacionados positivamente com o número de subsidiárias e foi o que encontrou nos resultados do seu estudo. Wu (2012) encontrou uma forte relação entre a complexidade da empresa e os honorários de auditoria.

No que tange ao crescimento, os honorários de auditoria variam conforme o crescimento da empresa. Nesse sentido, quanto mais a empresa cresce, aumenta o total de ativos, estoques, aumenta os riscos de auditoria, o que resulta em maior trabalho para a auditoria e consequentemente em honorários mais elevados (WU, 2012).

A capacidade de lucro e o nível de endividamento representam o risco do negócio. São fatores importantes que influenciam nos honorários de auditoria. Desta forma, a variável ROA representa a capacidade de lucro e a alavancagem o nível de dívida das empresas (WU, 2012). Para Yatim et al. (2006) e Hallak e Silva (2012), a relação entre alavancagem e honorários de auditoria deve ser positiva, tendo em vista que empresas mais alavancadas tem maiores chances de apresentar problemas de insolvência. Segundo Yatim et al. (2006) espera-se que o ROA esteja associado negativamente com os honorários de auditoria.

Yatim et al. (2006), encontrou uma relação positiva significativa entre os honorários de auditoria e a alavancagem, uma associação negativa entre honorários de auditoria e ROA. Entretanto, no estudo de Wu (2012) o ROA e a alavancagem não foram significativos.

Desta forma, como o ROA e alavancagem financeira, segundo Wu (2012) representam o risco de negócio, pode-se inferir que quanto maior o risco do negócio, maior tende a ser os honorários de auditoria.

Quanto maior as contas a receber e os estoques, maior o risco de auditoria e consequentemente, maiores serão os honorários de auditoria (WU, 2012). Desta forma, espera-se que essas variáveis apresentem uma relação positiva com os honorários de auditoria (YATIM et al., 2006; WU, 2012). No estudo de Yatim et al. (2006), as variáveis de controle contas a receber e estoques apresentaram uma relação positiva significativa com os honorários de auditoria. Os resultados do estudo de Wu (2012) demonstraram que contas a receber e estoques possuem relação com os honorários de auditoria.

Diante das variáveis apresentadas, tem-se a segunda hipótese da pesquisa: $\mathrm{H} 2$ : As variáveis de controle (empresa de auditoria, tamanho, número de subsidiárias, crescimento, ROA, alavancagem, contas a receber e estoque) possuem relação significativa com os honorários de auditoria.

\section{Elementos metodológicos da pesquisa}

0 presente estudo, quanto aos objetivos, classifica-se como descritivo, em razão de descrever o efeito da governança corporativa nos honorários de auditoria. No que se refere aos procedimentos técnicos, trata-se de uma pesquisa documental, ao utilizar-se de dados disponíveis na base de dados Economática ${ }^{\circledR}$, no sitio da BM\&FBovespa e nos formulários de referência das empresas. Quanto a abordagem do problema, o estudo identifica-se como quantitativo.

A população do presente estudo compreendeu todas as empresas listadas na Bolsa de Valores, Mercadorias e Futuros de São Paulo (BM\&FBOVESPA). A amostra é composta pelas empresas que possuíam todas as informações necessárias para a realização da pesquisa no ano de 2013, totalizando assim, 214 (duzentos e quatorze) empresas.

Os dados foram coletados na base de dados Economática ${ }^{\circledR}$, no sítio da BM\&FBovespa e nos formulários de referência das empresas do ano de 2013. A coleta de dados ocorreu no mês de agosto de 2014. Na base de dados Economática buscou-se os dados dos indicadores econômicofinanceiros, no sítio da BM\&FBovespa verificou-se o nível de Governança Corporativa das empresas, por fim, no formulário de referência foi coletado o valor pago de honorários de auditoria, o tipo de empresa de auditoria e o número de subsidiárias consolidadas. Por meio do Quadro 3 apresentam-se as variáveis do estudo.

\begin{tabular}{|c|c|c|c|}
\hline Variável & Descrição & Coleta & Autores \\
\hline \multicolumn{4}{|c|}{ Variável dependente } \\
\hline HonAud & $\begin{array}{l}\text { Valor pago de } \\
\text { honorários de } \\
\text { auditoria no } \\
\text { ano corrente. }\end{array}$ & $\begin{array}{c}\text { Formulário } \\
\text { de } \\
\text { Referência - } \\
\text { Item } 2.1\end{array}$ & $\begin{array}{c}\text { Griffin et al. } \\
(2008), \text { Wu } \\
(2012) \text {, Hallak e } \\
\text { Silva (2012), } \\
\text { Bortolon et al. } \\
\text { (2013). }\end{array}$ \\
\hline \multicolumn{4}{|c|}{ Variáveis independentes } \\
\hline GovCorp & $\begin{array}{c}\text { Variável } \\
\text { dummy: } 1 \text { se } \\
\text { faz parte do } \\
\text { nível de } \\
\text { governança } \\
\text { corporativa e } 0 \\
\text { caso contrário. }\end{array}$ & $\begin{array}{c}\text { Sítio da } \\
\text { BM\&FBovesp } \\
\text { a }\end{array}$ & $\begin{array}{c}\text { Griffin et al. } \\
\text { (2008), Wu } \\
\text { (2012), Hallak e } \\
\text { Silva (2012), } \\
\text { Bortolon et al. } \\
\text { (2013). }\end{array}$ \\
\hline \multicolumn{4}{|c|}{ Variáveis de Controle } \\
\hline Big4 & $\begin{array}{c}\text { Variável } \\
\text { dummy: } 1 \text { se } \\
\text { auditada por } \\
\text { empresa de } \\
\text { auditoria Big } \\
\text { Four e } 0 \text { caso } \\
\text { contrário. }\end{array}$ & $\begin{array}{c}\text { Formulário } \\
\text { de } \\
\text { Referência - } \\
\text { Item } 2.1\end{array}$ & $\begin{array}{l}\text { Francis (1984), } \\
\text { Choi et al. } \\
(2008) \text {, Wu } \\
\text { (2012), Hallak e } \\
\text { Silva, (2012). }\end{array}$ \\
\hline Tam & $\begin{array}{l}\text { Logaritmo } \\
\text { natural dos } \\
\text { ativos totais. }\end{array}$ & Economática & $\begin{array}{l}\text { Yatim et al. } \\
\text { (2006), Wu } \\
\text { (2012), Hallak e } \\
\text { Silva (2012). }\end{array}$ \\
\hline Subs & $\begin{array}{c}\text { Número de } \\
\text { subsidiárias } \\
\text { consolidadas. }\end{array}$ & $\begin{array}{c}\text { Formulário } \\
\text { de } \\
\text { Referência - } \\
\text { Item } 8.1\end{array}$ & $\begin{array}{c}\text { Yatim et al. } \\
(2006), \text { Wu } \\
(2012) .\end{array}$ \\
\hline $\begin{array}{c}\text { CrescEmpre } \\
\text { sa }\end{array}$ & Q de Tobin. & Economática & Wu (2012). \\
\hline ROA & $\begin{array}{l}\text { Rentabilidade } \\
\text { do Ativo. }\end{array}$ & Economática & $\begin{array}{c}\text { Yatim et al. } \\
\text { (2006), Wu } \\
\text { (2012). }\end{array}$ \\
\hline Alav & $\begin{array}{l}\text { Alavancagem } \\
\text { Financeira. }\end{array}$ & Economática & $\begin{array}{l}\text { Yatim et al. } \\
\text { (2006), Wu } \\
\text { (2012), Hallak e } \\
\text { Silva, (2012). }\end{array}$ \\
\hline CtasRec & $\begin{array}{l}\text { Contas a } \\
\text { receber/ativo } \\
\text { total. }\end{array}$ & Economática & $\begin{array}{l}\text { Yatim et al. } \\
(2006), \mathrm{Wu} \\
(2012) \text {. }\end{array}$ \\
\hline Estoque & $\begin{array}{c}\text { Estoque/Ativo } \\
\text { Total. }\end{array}$ & Economática & $\begin{array}{c}\text { Yatim et al. } \\
\text { (2006), Wu } \\
\text { (2012). }\end{array}$ \\
\hline
\end{tabular}

Quadro 3 - Variáveis do estudo

Fonte: Dados da pesquisa.

Os dados foram tabulados em planilha eletrônica e foram analisados por meio de estatística descritiva, testes de aleatoriedade, normalidade, homocedasticidade e regressão 
linear múltipla, com a utilização do software SPSS $®$.

\section{Apresentação e discussão dos resultados}

São apresentadas nesta seção, a descrição e análise dos dados. Inicialmente realizou-se análise descritiva dos dados, e em seguida foram observados os testes de aleatoriedade, normalidade e homocedasticidade, os quais são fundamentais para realizar a técnica de regressão linear múltipla. Na Tabela 1 apresenta-se a análise descritiva dos dados.

Tabela 1 - Análise descritiva

\begin{tabular}{l|l|l|l|l|l}
\hline Variáveis & Mínimo & Máximo & Média & Mediana & $\begin{array}{l}\text { Desvio } \\
\text { Padrão }\end{array}$ \\
\hline Tam & 10,635 & 20,440 & 14,788 & 14,941 & 1,7360 \\
\hline CresEmpr & 0,070 & 8,800 & 0,986 & 0,893 & 0,6849 \\
\hline ROA & $-51,800$ & 26,500 & 2,144 & 2,800 & 9,4758 \\
\hline Alav & $-89,511$ & 1200,297 & 8,227 & 1,525 & 83,1823 \\
\hline CtasRec & 0,011 & 0,926 & 0,177 & 0,134 & 0,1420 \\
\hline Estoque & 0,000 & 0,414 & 0,098 & 0,094 & 0,0900 \\
\hline HonAud & 0,000 & 18,099 & 13,161 & 12,975 & 1,3511 \\
\hline Big4 & 0,000 & 1,000 & 0,750 & 1,000 & 0,4340 \\
\hline Subs & 0,000 & 411,000 & 17,292 & 5,000 & 47,4534 \\
\hline
\end{tabular}

Fonte: Dados da pesquisa.

Com base na Tabela 1, observou-se que a variável tamanho da empresa (Tam) apresentou desvio padrão de 1,7360 , o que indica que os tamanhos das empresas são similares, com uma média de 14,788 em milhares. A variável crescimento da empresa (CresEmpr), com desvio padrão de 0,6849 demonstrou que as empresas analisadas cresceram na mesma proporção no ano de 2012 para o ano de 2013. A variável rentabilidade do ativo (ROA) também apresentou valores parecidos entre as empresas, no entanto cabe ressaltar que algumas empresas apresentaram valores negativos. A variável alavancagem (Alav), com desvio padrão de 83,1823 demonstrou que houve grande discrepância do valor da alavancagem em relação à média que foi de 8,227 , e também por apresentar valor mínimo de - 89,5 e valor máximo de 1.200,3. As variáveis contas a receber (CtasRec) e estoque (Estoque) não tiveram dispersão de valores entre as empresas, o que pode ser visto no desvio padrão de 0,1420 e 0,0900, respectivamente.

A variável honorários de auditoria (HonAud) apresentou valor mínimo, máximo e média de 0,000; 18,099 e 13,161 , respectivamente, com similaridade entre os valores por demonstrar desvio padrão de 1,3411. Quanto ao tipo de auditoria, as empresas apresentaram uma média de 0,750 , ou seja, que a maior parte das empresas são auditadas por Big Four (Big4). No que tange as subsidiárias das empresas analisadas (Subs), observou-se que algumas empresas não possuem subsidiárias, enquanto outras apresentaram um grande número de subsidiárias, com valor máximo de 411 .

A Tabela 2 apresenta os testes de aleatoriedade, normalidade e homocedasticidade sobre os dados analisados, que são os pressupostos fundamentais para a realização da técnica de regressão linear.
Tabela 2 - Testes de aleatoriedade, normalidade e homocedasticidade

\begin{tabular}{|c|c|c|}
\hline Pressupostos & Testes & Hipóteses \\
\hline Aleatoriedade & $\begin{array}{l}\text { Durbin-Watson. } \\
\text { Estatística DW = } \\
2,1032 \\
\text { Valor-p } \\
0,9071 ; \\
\text { Autocorrelação } \\
\text { dos resíduos = - } \\
0,0516\end{array}$ & $\begin{array}{l}\text { Inexiste } \\
\text { autocorrelação } \\
\text { de primeira } \\
\text { ordem entre os } \\
\text { resíduos. }\end{array}$ \\
\hline Normalidade & $\begin{array}{l}\text { Shapiro-Wilk: } \\
\text { Estatística SW = } \\
0,5223 ; \text { Valor-p } \\
=0,0000\end{array}$ & $\begin{array}{l}\text { A distribuição dos } \\
\text { resíduos é } \\
\text { normal. }\end{array}$ \\
\hline Homocedasticidade & $\begin{array}{l}\text { Levene: } \\
\text { Estatística } F= \\
0,5990 ; \quad \text { Valor-p } \\
=0,4398\end{array}$ & $\begin{array}{l}\text { A variância dos } \\
\text { erros é uniforme. }\end{array}$ \\
\hline
\end{tabular}

Fonte: Dados da pesquisa.

Para testar a aleatoriedade foi aplicado o teste de Durbin-Watson, que apresentou valor de 2,1197. De acordo com Marôco (2011) este valor deve ser próximo de 2, o qual indica inexistência de autocorrelação de primeira ordem entre os resíduos. Desta forma, o modelo do estudo atendeu a este pressuposto.

O teste de Shapiro-Wilk observa a "distribuição de frequência acumulada de um conjunto de valores observados da amostra com uma distribuição esperada ou teórica" (FÁVERO et al., 2009, p. 112) e o teste de Levene observa a homocedasticidade dos dados, de acordo com Marôco (2011) este teste verifica se a variância populacional são homogêneas. Desta forma, verificou-se que os dados analisados atenderam ao pressuposto de normalidade e homocedasticidade, ao apresentarem distribuição dos resíduos de forma normal e variância dos erros uniforme, respectivamente.

$\mathrm{Na}$ Tabela 3 visualiza-se o resumo do modelo.

Tabela 3 - Resumo do modelo

\begin{tabular}{c|c|c|c|c}
\hline Modelo & $\mathrm{R}$ & $\mathrm{R}$ & $\mathrm{R}$ & Erro \\
quadrado & $\begin{array}{c}\text { quadrado } \\
\text { ajustado }\end{array}$ & $\begin{array}{c}\text { padrão da } \\
\text { estimativa }\end{array}$ \\
\hline 1 & 0,398 & 0,159 & 0,121 & 2,5365 \\
\hline
\end{tabular}

Fonte: Dados da pesquisa.

0 valor de $\mathrm{R}$ disposto na Tabela 3 apresenta explicação do modelo de 0,398 , o que indica que as variáveis independentes utilizadas possuem uma associação de $39,8 \%$ com a variável dependente. Deste modo, verifica-se que 0 modelo foi eficaz em prever os honorários de auditoria (HonAud) por meio das variáveis utilizadas. Na Tabela 4 demonstra-se a significância do modelo. 
Tabela 4 - ANOVA

\begin{tabular}{l|l|l|l|l|l|l}
\hline \multicolumn{2}{l|}{ Modelo } & $\begin{array}{l}\text { Soma dos } \\
\text { Quadrados }\end{array}$ & Df & $\begin{array}{l}\text { Quadrado } \\
\text { Médio }\end{array}$ & F & Sig. \\
\hline \multirow{3}{*}{1} & Regressão & 245,256 & 9 & 27,251 & 4,236 & 0,000 \\
\cline { 2 - 7 } & Resíduos & 1299,605 & 202 & 6,434 & & \\
\cline { 2 - 8 } & Total & 1544,861 & 211 & & & \\
\hline
\end{tabular}

Fonte: Dados da pesquisa

O Valor de Sig de 0,000, menor do que o valor de 0,05 indica que o modelo apresenta significância, ou seja, as variáveis independentes influenciam nos honorários de auditoria (HonAud). Verificam-se por meio da Tabela 5 os coeficientes das variáveis analisadas.

Tabela 5 - Coeficientes

\begin{tabular}{|c|c|c|c|c|c|c|}
\hline & Modelo & $\begin{array}{r}\text { Coefici } \\
\text { padro }\end{array}$ & $\begin{array}{l}\text { ites não } \\
\text { izados }\end{array}$ & $\begin{array}{l}\text { Coeficientes } \\
\text { padronizados }\end{array}$ & $\mathrm{T}$ & Sig. \\
\hline & & B & $\begin{array}{l}\text { Modelo } \\
\text { padrão }\end{array}$ & Beta & & \\
\hline & (Constante) & 6,457 & 1,915 & & 3,372 & 0,001 \\
\hline & Tam & 0,390 & 0,130 & 0,251 & 2,998 & $0,003^{*}$ \\
\hline & CresEmpr & 0,219 & 0,262 & 0,056 & 0,838 & 0,403 \\
\hline & ROA & $-0,029$ & 0,020 & $-0,101$ & 1,472 & 0,143 \\
\hline 1 & Alav & $-0,000$ & 0,002 & $-0,014$ & $\begin{array}{c}- \\
0,210\end{array}$ & 0,834 \\
\hline & CtasReceber & $-2,487$ & 1,420 & $-0,129$ & 1,752 & $0,081^{*}$ \\
\hline & Estoque & 0,952 & 2,115 & 0,032 & 0,450 & 0,653 \\
\hline & Big4 & 0,780 & 0,503 & 0,125 & 1,550 & 0,123 \\
\hline & Subs & 0,004 & 0,004 & 0,070 & 1,003 & 0,317 \\
\hline & GovCorp & 0,055 & 0,417 & 0,010 & 0,133 & 0,894 \\
\hline
\end{tabular}

Fonte: Dados da pesquisa

As variáveis que apresentaram significância ao nível de $5 \%$ e $10 \%$ para predizer a variável dependente honorários de auditoria (HonAud) foram tamanho da empresa (Tam) e contas a receber (CtasReceber), respectivamente. As demais variáveis utilizadas não se apresentaram significativas.

Quanto aos coeficientes das variáveis, observou-se que o tamanho da empresa (Tam) possui relação positiva com os honorários de auditoria (HonAud), o que indica que quanto maior o tamanho da empresa (Tam) maior os honorários de auditoria (HonAud). A variável contas a receber (CtasReceber) apresentou relação negativa com a variável dependente, ou seja, o saldo de contas a receber impacta na diminuição dos honorários de auditoria (HonAud).

Diante dos resultados encontrados, rejeita-se a Hipótese 1 de que o nível de governança corporativa possui relação significativa com os honorários de auditoria, ao não apresentar significância estatística entre as variáveis governança corporativa (GovCorp) e honorários de auditoria (HonAud). Este achado corrobora com os resultados encontrados por Bortolon et al. (2013), os quais também não verificaram significância entre 0 nível de governança corporativa e os honorários de auditoria. Entretanto, vão de encontro com os achados de Griffin et al. (2008), Hallak e Silva (2012), que encontraram em seus estudos relação positiva e significativa entre governança corporativa e honorários de auditoria.

Wu (2012) argumenta que a governança corporativa possui relação com os honorários de auditoria, em que níveis baixos de governança corporativa por remeter riscos impactam em elevados gastos com auditoria e também por apresentar nível alto de governança corporativa exige maior trabalho de auditoria, para sinalizar melhor o valor da empresa ao mercado, acarretando em valores elevados de auditoria. Todavia, esta relação significativa entre governança corporativa e honorários de auditoria não foi visualizada na presente pesquisa.

A Hipótese 2, que testa se as variáveis de controle (empresa de auditoria, tamanho, número de subsidiárias, crescimento, ROA, alavancagem, contas a receber e estoque) possuem relação significativa com os honorários de auditoria, pode ser aceita parcialmente, visto que somente as variáveis tamanho da empresa (Tam) e contas a receber (CtasReceber) apresentaram-se significativas.

O tamanho da empresa apresentou relação positiva com os honorários de auditoria (HonAud), o que vai ao encontro dos estudos de Yatim et al. (2006), Wu (2012) e Hallak e Silva (2012). A variável contas a receber (CtasReceber) apresentou relação negativa e significativa com os honorários de auditoria, o que vai de encontro dos resultados de Yatim et al. (2006) e Wu (2012), que encontraram relação positiva. Para estes autores, o saldo elevado de contas a receber representa maior risco de auditoria.

De forma geral, observou-se que empresas maiores, por possuírem atividades de negócios maiores (WU, 2012) e serviços complexos que demandam maior tempo de serviço (HALLAK; SILVA, 2012) acarretam em honorários de auditoria com valor elevado. O saldo elevado de contas a receber das empresas analisadas não representou risco empresarial para a auditoria, não influenciando no aumento dos honorários de auditoria, mas sim na sua diminuição.

\section{Considerações finais}

O presente estudo teve por objetivo verificar o efeito da governança corporativa nos honorários de auditoria em empresas brasileiras, para isto utilizou-se como procedimentos metodológicos análise descritiva, quanto aos procedimentos do estudo utilizou-se de análise documental e referente à abordagem do problema, configurou-se como quantitativo. A população compreendeu todas as empresas listadas na Bolsa de Valores Mercadorias e Futuros BM\&FBOVESPA. A amostra foi composta por 214 empresas, que dispunham de todas as informações necessárias para a realização do estudo. 0 período de análise correspondeu ao ano de 2013.

Os dados econômicos e financeiros foram coletados na base de dados Economática e as informações sobre as características da empresa, como o tipo de auditoria e o número de subsidiárias, bem como o nível de governança corporativa e honorários de auditoria, foram coletados nos formulários de referência das empresas analisadas no site da BM\&FBOVESPA. A análise dos dados foi possibilitada pela utilização de técnicas estatísticas, como análise descritiva e regressão linear múltipla, por meio do software SPSS.

Com base nos resultados encontrados, pode-se rejeitar 
a Hipótese 1 , ao não se verificar relação significativa entre governança corporativa e honorários de auditoria, e aceitar parcialmente a Hipótese 2, visto que somente o tamanho da empresa e contas a receber apresentaram relação significativa com os honorários de auditoria. Pode-se inferir, de acordo com a amostra analisada, que a governança corporativa, o crescimento, alavancagem da empresa, estoque, número de subsidiárias, rentabilidade do ativo e o tipo de auditoria não impactaram significativamente nos valores pagos pelas empresas aos serviços de auditoria realizados por firmas independentes.

Verificou-se que quanto maior o tamanho da empresa, maiores os honorários de auditoria e que o saldo de contas a receber não impactou no aumento dos honorários de auditoria, mas sim impactou na diminuição dos honorários. Empresas maiores, por possuírem atividades de negócios maiores e serviços complexos que demandam maior tempo de serviço desembolsam maiores honorários de auditoria. E as contas a receber das empresas analisadas não acarretaram em risco empresarial para a auditoria, não influenciando no aumento dos honorários de auditoria.

A governança corporativa, de acordo com Wu (2012), é um meio de sinalização das empresas ao mercado, informando aos usuários que possuem práticas de governança e por isso são organizadas e transparentes, incentivando investidores e sócios em aumentar a relação com a empresa. Por tal motivo, a governança corporativa em uma empresa ganharia proporção da mesma forma que os honorários de auditoria, ou seja, quanto maior o nível de governança corporativa, maiores os honorários de auditoria, por estes terem de realizar seus serviços, garantindo a transparência organizacional. No presente estudo, não se verificou relação significativa entre governança e honorários de auditoria, contudo, ressalta-se que a relação demonstrou-se positiva, confirmando a hipótese do autor, de que a governança corporativa é um meio de sinalização das empresas ao mercado, e por isso pagam valores mais elevados de auditoria.

Sugere-se como pesquisas futuras, a análise de outras formas de sinalização da empresa ao mercado e que impactam nos honorários de auditoria, como os comitês internos que são formados, participação da empresa em grupos seletos, como índices de liquidez e índice de sustentabilidade empresarial. A teoria da sinalização em estudos de ciências sociais aplicadas encontra-se ainda incipiente, contribuindo desta forma, a realização de novos estudos como outros métodos de sinalização da empresa.

\section{Referências}

BM\&FBOVESPA. Segmentos de listagem.

BORTOLON, P. M.; SARLO NETO, A.; SANTOS, T. B. (2013). Custos de auditoria e governança corporativa. Revista Contabilidade \& Finanças, v. 24, n. 61, p. 27-36, 2013.

CAI, C.; DUXBURY, D.; KEASEY, K. (2007). A new test of signaling theory. Finance Letters, v. 5, n. 2, p. 1-5.

CARVALHO, A. G. (2002). Governança corporativa no Brasil em perspectiva. Revista de Administração, v. 37, n. 3, p. 1932.

CHOI, J.-H.; KIM, J. B.; LIU, X.; SIMUNIC, D. A. (2008). Audit
Pricing, Legal Liability Regimes, and Big 4 Premiums: Theory and Cross-country Evidence. Contemporary Accounting Research, v. 25, n. 1, p. 55-99.

DALMÁCIO, F. Z. (2009). Mecanismos de governança $e$ acurácia das previsões dos analistas do mercado brasileiro: uma análise sob a perspectiva da teoria da sinalização. Tese (Doutorado em Ciências Contábeis), Departamento de Contabilidade e Atuária da Faculdade de Economia, Administração e Contabilidade, Universidade de São Paulo, São Paulo, Brasil.

DIONNE, G.; OUEDERNI, K. (2010). Corporate risk management and dividend signaling theory. Finance Research Letters, v. 8, n. 4, p. 188-195.

EHIKIOYA, B. I. (2009). Corporate governance structure and firm performance in developing economies: evidence from Nigeria. Corporate Governance, v. 9, n. 3, p. 231-243.

FÁVERO, L. P.; BELFIORE, P.; SILVA, F. L.; CHAN, B. L. (2009). Análise de Dados: Modelagem Multivariada para tomada de decisões. Rio de Janeiro: Elsevier.

FAZLZADEH, A.; HENDI, A. T.; MAHBOUBI, K. (2011). The Examination of the Effect of Ownership Structure on Firm Performance in Listed Firms of Tehran Stock Exchange Based on the Type of the Industry. International Journal of Business and Management, v. 6, n. 3, p. 249-266.

FRANCIS, J. R. (1984). The effect of audit firm size on audit prices: A study of the Australian market. Journal of accounting and Economics, v. 6, n. 2, p. 133-151.

GRIFFIN, P. A.; LONT, D. H.; SUN, Y. (2008). Corporate governance and audit fees: evidence of countervailing relations. Journal of Contemporary Accounting \& Economics, v. 4, n.1, p. 18-49.

HALLAK, R. T. P.; SILVA, A. L. C. (2012). Determinantes das despesas com serviços de auditoria e consultoria prestados pelo auditor independente no Brasil. Revista Contabilidade \& Finanças, v. 23, n. 60, p. 223-231.

HASAN, A.; BUTT, S. A. (2009). Impact of ownership structure and corporate governance on capital structure of Pakistani listed companies. International Journal of Business and Management, v. 4, n. 2, p. 50-57.

IBGC. (2004). Código das Melhores Práticas de Governança Corporativa. São Paulo: IBGC.

LA PORTA, R.; LOPEZ-DE-SILANES, F.; SHLEIFER, A.; VISHNY, R. (2000). Investor protection and corporate governance. Journal of financial economics, v. 58, n. 1, p. 3-27.

LOVE, I. (2010). Corporate governance and performance around the world: what we know and what we don't. The World Bank Research Observer, p. Ikp 030.

MARÔCO, J. (2011). Análise Estatística com o SPSS statistics. $5^{\mathrm{a}}$ ed. Pero Pinheiro: ReportNumber.

SHLEIFER, A.; VISHNY, R. W. (1997). A survey of corporate governance. The journal of finance, v. 52, n. 2, p. 737-783.

SPENCE, M. (1973). Job market signaling. The quarterly journal of Economics, p. 355-374.

WANG, R. Z.; Ó HOGARTAIGH, C.; VAN ZIJL, T. (2009). A Signaling Theory of Accounting Conservatism. Tony, A 
Signaling Theory of Accounting Conservatism.

WU, X. (2012). Corporate governance and audit fees: Evidence from companies listed on the Shanghai Stock Exchange. China Journal of Accounting Research, v. 5, n. 4, p. 321-342.

YATIM, P.; KENT, P.; CLARKSON, P. (2006). Governance structures, ethnicity, and audit fees of Malaysian listed firms. Managerial Auditing Journal, v. 21, n. 7, p. 757-782. 